\title{
A Simulation Model Articulation of the REA Ontology
}

\author{
Wim Laurier and Geert Poels \\ Department of Management Information and Operational Management, Faculty of Economic \\ and Business Administration, Ghent University, Tweekerkenstraat 2, 9000 Ghent, Belgium \\ \{wim.laurier, geert.poels\} @ugent. be
}

\begin{abstract}
This paper demonstrates how the REA enterprise ontology can be used to construct simulation models for business processes, value chains and collaboration spaces in supply chains. These models support various high-level and operational management simulation applications, e.g. the analysis of enterprise sustainability and day-to-day planning. First, the basic constructs of the REA ontology and the ExSpect modelling language for simulation are introduced. Second, collaboration space, value chain and business process models and their conceptual dependencies are shown, using the ExSpect language. Third, an exhibit demonstrates the use of value chain models in predicting the financial performance of an enterprise.
\end{abstract}

Keywords: Resource-Event-Agent ontology, supply chain, enterprise, accounting model, simulation.

\section{Introduction}

This paper demonstrates how an enterprise ontology can be useful in building various kinds of business simulation models. Such simulation models predict the behaviour of newly designed business systems before they are implemented. In technological fields, simulation models are useful when the cost of error associated with R\&D is high. For instance, when a new plane type is designed, its behaviour is simulated before the actual plane is constructed as building a plane is expensive and time consuming and operating a potentially flawed experimental plane might imply loss of lives. Also in business, simulation models are useful for predicting the effects of business changes and redesign actions. For instance, enterprises that suffer liquidity constraints in an environment where external funding is scarce (e.g. unsteady banks and capital markets) may also encounter high costs of error since redesigns that worsen liquidity constraints may immediately imply the end of an enterprise's existence.

The enterprise ontology we look at is the Resource-Event-Agent (REA) ontology [1-5], which originates in a semantic accounting data model that was designed for a shared data environment in which accountants and non-accountants maintain information about the same economic phenomena [6]. Apart from accounting systems design, the REA ontology is applied in accounting education, model-driven systems design, supply-chain collaboration and knowledge representation [7].

The accounting background of the REA ontology allows simulation model builders to inject an economic rationale into their simulation models, and in particular to integrate models showing financial flows with the more traditional models showing logistic 
flows and workflows [8]. So far, this integration of financial and logistic flows was only offered by the e3-value ontology [9] at a very high abstraction level. The explicit connection between logistic processes and financial processes increases the configurability and reusability of the simulation models. For instance, a business process simulation model for determining process capacity, cycle time and process time can easily be reconfigured for estimating the value of and cost of capital for the 'work in progress' that will appear as an asset on the balance sheet. Another advantage of REA ontology-based simulation models is that the combined effects of redesigning individual business processes and workflows can be simulated in enterprise or supply chain level models, which may help to identify synergies and interferences between the redesign actions taken on different processes or workflows.

The idea of using the REA ontology for simulation purposes comes from Church and Smith [10], who consider it the best-of-class supply chain and business process ontology for constructing business simulation models. Church and Smith merely explore the idea of ontology-based simulation models by using REA for modelling continuous flows in an enterprise using System Dynamics ${ }^{1}$. The simulation of continuous flows solely supports high-level management applications (e.g. long-term capacity planning). We provide further evidence of the REA ontology's simulation modelling power by means of REA ontology-based models for discrete event simulation. which supports various kinds of operational management applications (e.g. dayto-day planning). This type of simulation is based on the identification of individual cases for which a lifecycle can be developed based upon case characteristics and on the use of decision algorithms for specific process stages (e.g. if a loan is rated above average it will be approved and granted). For the articulation of the discrete event simulation models, the ExSpect ${ }^{2}$ simulation tool will be used.

Section 2 presents the constructs of the REA ontology and the simulation language of the ExSpect tool. Section 3 shows how discrete event business simulation models for enterprises that engage in supply chains, including models for business processes, value chains and collaboration spaces, are constructed using the REA ontology. Section 4 then compares four alternative value chain designs, on their financial performance (e.g. turnover, total liabilities). Section 5 ends the paper with conclusions and ideas for further research.

\section{Overview of the REA Ontology and the ExSpect Simulation Language}

\subsection{The ExSpect Simulation Language}

The ExSpect simulation language is a visual modelling language that is based on highlevel (i.e. hierarchical, timed and coloured) Petri-nets. Petri-nets model processes by means of tokens, places and transitions. The distribution of the tokens over the places in a Petri-net represents the state of the process. The transitions specify a strict precedence relation between the places a token can occupy during the execution of a process. Hence, transitions model events that change the state of the process. Coloured

\footnotetext{
${ }^{1}$ http://www.systemdynamics.org/

${ }^{2}$ http://www.exspect.com/
} 
Petri-nets allow tokens to have attributes describing them, which means that the state of a process is also determined by the values that the attributes of the tokens take. Hierarchical Petri-nets allow decomposition structures such that a Petri-net can be refined by other Petri-nets [11]. In classic Petri-nets, all transitions represent atomic events, while in hierarchical Petri-nets transitions can represent complex events (i.e. events composed of other events). Finally, timed Petri-nets allow transitions to have a duration, which makes them useful for representing non-instantaneous events.

In coloured Petri-nets, the attributes of a token can be used to give a stable identity to the individual that is represented by the token. In workflow modelling, such an individual with a stable identity is called a case [8] (e.g. a document that needs to be processed). When these identity bearing tokens reside in a place, they represent a lifecycle phase of such a case. Consequently, transitions define strict precedence relations between the lifecycle phases of a case or model a precedence relation between different cases.

\subsection{The REA Ontology}

A remarkable conceptual dichotomy in REA is the difference between economic phenomena and business phenomena. The former create or represent economic value (e.g. the acceptance of a sales order), while the latter are considered worth monitoring and controlling although they do not directly create or represent economic value (e.g. the registration of an accepted sales order). For the injection of economic rationale into business simulation models, this distinction between value bearing phenomena (i.e. economic) and value supporting phenomena (i.e. business) is primordial as it discriminates the economic rationale driven business logic from the operational implementation of the business logic. The economy/business dichotomy in the REA ontology relates closely to Porter's [12] discrimination of primary activities, which construct a scarce and valuable product, and support activities, which allow primary activities to take place. Primary activities directly contribute to the creation of economic value and are represented in the REA ontology as Economic Events. Support activities facilitate and enable this value creation and are represented in the REA ontology as Business Events.

Resources in the REA ontology are defined as goods, services or rights that have utility and are under the control of a legal or natural person. Economic resources can be distinguished from business resources because the former are inevitably scarce, which motivates their economic value $[3,6]$. Business resources support business activities without being scarce (e.g. information can be replicated/duplicated at very low cost). Events are occurrences in time that relate subsequent process states to each other. Economic events are discriminated from business events as the former involve gaining (i.e. increment) or losing (i.e. decrement) control over economic resources, in contrast to the latter [3,6]. Agents are natural persons that act on behalf of economic units (e.g. enterprises). Economic agents are accountable for, participate in or initiate economic events, whereas business agents are accountable for, participate in or initiate business events. Units determine the scope of the context in which economic activities take place. Economic units represent financially self-sustaining entities, while business units characterize non-self-supporting structures that are usually embedded in economic units. Table 1 lists some examples for each basic REA construct presented here. 
Table 1. Examples of basic REA Concepts

\begin{tabular}{l|ll}
\hline \multirow{2}{*}{ Resource } & \multicolumn{1}{|l}{ Economic } & Business \\
\cline { 2 - 3 } Event & $\begin{array}{l}\text { e.g. goods, infrastructure, } \\
\text { services, machines, rights }\end{array}$ & $\begin{array}{l}\text { e.g. documents, manuals, } \\
\text { schedules, signals }\end{array}$ \\
& $\begin{array}{l}\text { e.g. payment, purchase, } \\
\text { consumption, production, } \\
\text { sale }\end{array}$ & $\begin{array}{l}\text { e.g. scheduling a production } \\
\text { run, sending an invoice }\end{array}$ \\
Agent & $\begin{array}{l}\text { e.g. cashier, production line } \\
\text { operator, salesperson }\end{array}$ & $\begin{array}{l}\text { e.g. accounting clerk, } \\
\text { production planner }\end{array}$ \\
Unit & e.g. enterprise, organisation & e.g. department, team \\
\hline
\end{tabular}

\section{Economic Rationale Models}

In this section, it is shown how the economic rationale that is expressed in the REA ontology, can be represented in collaboration space, value chain and business process simulation models. Collaboration space models encompass the supply chain view on economic phenomena and focus on (physical) resource flows between economic units. Such models are especially useful for representing and simulating logistic, service and money flows between supply chain partners. Value chain $[4,5]$ models represent supply chain partners as extended open systems [13] that sustain their continuity by enforcing economic reciprocity. This kind of simulation model can be used for assessing the financial characteristics (e.g. assets, liabilities, turnover) of individual supply chain partners. Business process models show the actual underlying processes. These models allow analysing operational process characteristics (e.g. bottlenecks, cycle time, capacity).

The collaboration space model in fig. 1 shows the interactions between three supply chain partners, which we refer to as the enterprise (i.e. the supply chain partner that is the focal point of the simulation model), the supplier of the enterprise and the customer of the enterprise. This collaboration space model shows both business (i.e. offer, order and invoice) and economic (i.e. product and money) resources that are transferred between these partners. The underlying business processes, which can be modelled by decomposing the Petri-net, specify how an offer is generated and transformed into an order; how this order triggers a product transfer and the creation of an invoice and how this invoice triggers a money transfer. Since the economic units (i.e. Supplier, Enterprise, Customer) in the model are modelled as complex transitions (i.e. yellow boxes) that cover more complex underlying processes, each of the resource transfers (e.g. ProductSupp) in the collaboration space is allowed to occur individually, unless the underlying business process specifies otherwise.

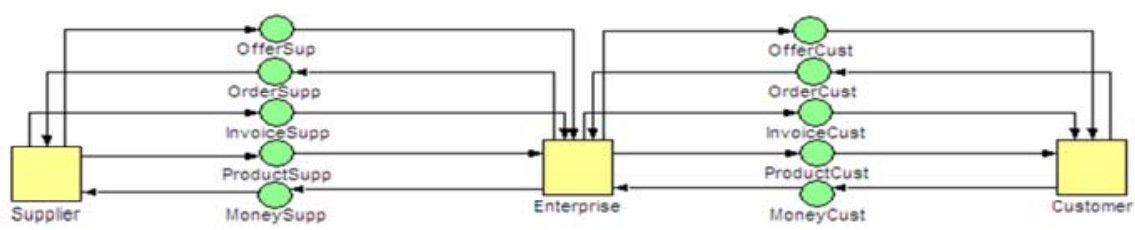

Fig. 1. Collaboration space model for an enterprise with one supplier and one customer 
Next to business processes, also value chains, which introduce the economic rationale for participating in a supply chain, determine the behaviour of economic units (e.g. illiquidity may force an economic unit to halt its business processes). Fig. 2 shows a value chain model for the enterprise that was the focal point in the collaboration space model of fig. 1. This value chain model presents a generic and extensible template for enterprises participating in supply chains. This value chain model consists of four cycles $[4,5]$. The acquisition cycle, which is shown at the left-hand side of fig. 2, models the interface with suppliers via a complex transition (called Acquisition_Cycle), representing a duality between the Product_Inflow transition and the Money_Outflow transition. This duality reflects an axiom of the REA ontology that states that "All events effecting an outflow must be eventually paired in duality relationships with events effecting an inflow and vice-versa"[2]. This means that economic rationale requires adequate compensation for the economic resources that leave an economic unit (i.e. the supplier's products must be paid for by the enterprise) and dictates the existence of requiting economic events for economic events that create claims and liabilities. Analogously, the revenue cycle, which is represented as the complex transition Revenue_Cycle at the right-hand side of fig. 2, shows the balance between the value of goods sold and the revenues that remunerate them. Similarly, the conversion cycle, which is represented as the complex transition Conversion_Cycle at the upper side of fig. 2, models the business unit in which the value creating transformation processes take place. Finally, the financing cycle, which is represented as the complex transition Finance_Cycle at lower side of fig. 2, models the business unit in which the process of approving payments and controlling budgets takes place. The template in fig. 2 can be extended by adding more acquisition, conversion, revenue financing cycles and transfers (e.g. the payroll cycle [5] that exchanges labour and money (i.e. wages) between the enterprise and its employees).

Next to the value chain (i.e. an aggregate of acquisition, conversion, revenue and financing cycles), which shows that the balance between incoming and outgoing money and product flows is essential for the sustainability of an economic unit's economic activities, the value chain model in fig. 2 is equipped with transfer events that represent the parts of an exchange process that an economic unit is accountable for. Fig. 2 assumes that the enterprise is accountable for both transfers that relate to its revenue cycle (i.e. product outflow and money inflow). The complete transfer economic event is modelled by connecting the decrement side of a transfer event under control of one economic unit (e.g. the TransferProduct transition between the OutflowProductO place and the ProductCust place on the right-hand side of fig. 2) to its increment side, which is under the control of a subsequent economic unit (and which would be shown, e.g. as the TransferProduct transition between the ProductSupp place and the InputProduct place, in the value chain model of that economic unit). Together, both transfer events form an economic event template [14], which starts with an economic resource decrement (i.e. outflow) and ends with an economic resource increment (i.e. inflow), that allows integrating the value chain models of different supply chain partner into one simulation model that can subsequently be shown in a reduced form (i.e. going one level up in the Petri-net decomposition hierarchy) as a collaboration space model. 


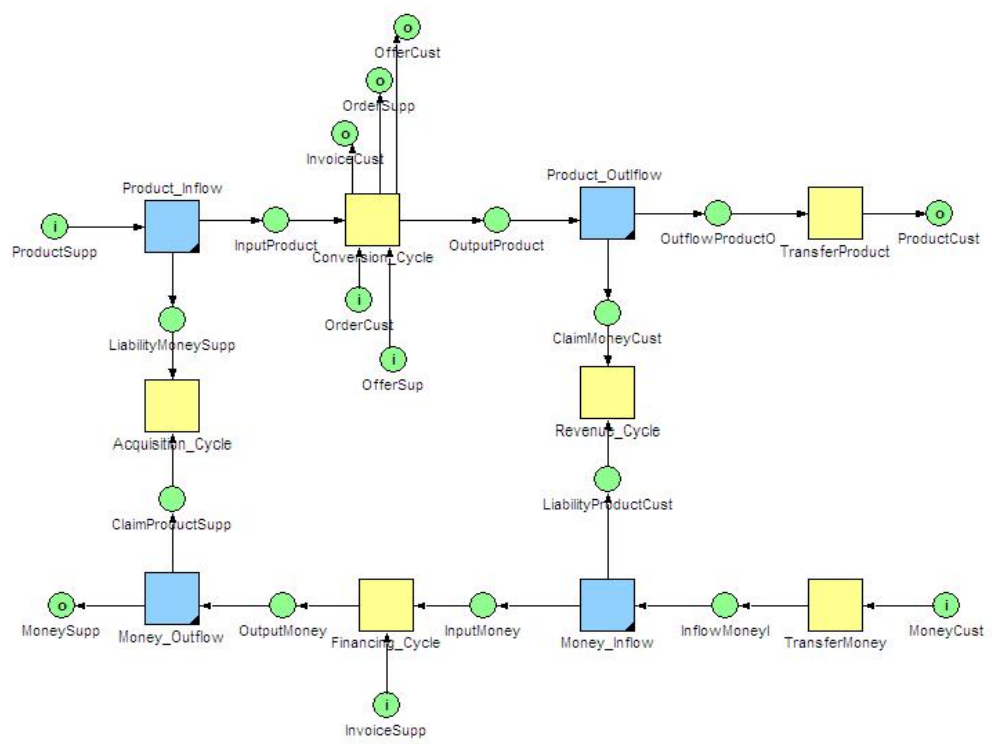

Fig. 2. Value chain model for the enterprise in the collaboration space model of Fig. 1

Fig. 3 depicts a simple business process which is part of the 'Conversion Cycle' business unit in fig. 2. It models a transformation economic event, which starts with an economic resource decrement and ends with an economic resource increment, that is triggered by an order (i.e. a business resource) and gives rise to the creation of an invoice (i.e. another business resource). The business events that are part of the economic event can be represented by further decomposing the TransformationProduct transition. Similarly, the business events that are part of the 'TransferProduct' and 'TransferMoney' economic events in fig. 2 can be represented in business process models that underlie these transfer economic events.

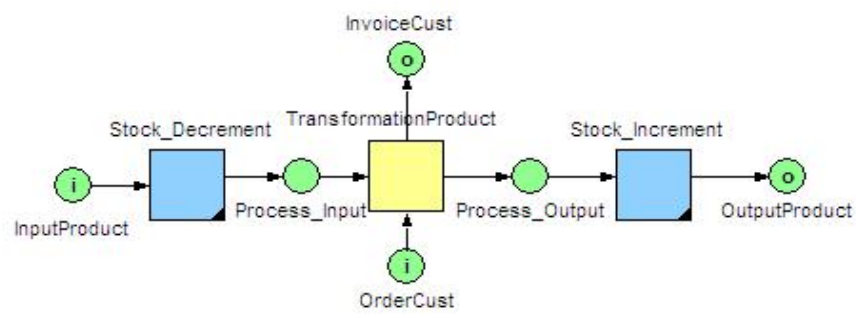

Fig. 3. Business process model for the conversion cycle of the enterprise in the value chain model of Fig. 2

\section{Exhibit: Alternative Value Chain Designs}

This section applies the templates presented in the preceding section, to evaluate four alternative theoretical business designs, on their financial performance (e.g. turnover, 
debt, value of work in progress). The initial value chain model (i.e. Design 0) ), which is modelled after fig. 7 and contained in a collaborations space model as shown in fig. 6 , has an acquisition cycle in which the supplier finances its sales to the enterprise for a 30 day period (i.e. term of payment), a conversion cycle that takes 50 days, a revenue cycle that offers a 30 day payment term to the customer, a product transfer that takes 3 days, a money transfer that takes 2 days and a financing cycle that takes 5 days. The first redesign (i.e. Design 1), which was implemented by duplicating 'Design 0' and changing the transformation business process model (see fig. 8) that underlies its conversion cycle, halves the duration of the conversion cycle (i.e. 50 to 25 days). The second redesign (i.e. Design 2) reduces the term of payment that is offered to the customer with 25 days (i.e. 30 to 5 days) and the third redesign shows the effect of a supplier that reduces the term of payment (i.e. 30 to 5 days) for the enterprise. The latter two redesigns are implemented by changing the characteristics of the invoicing process that is partially modelled as a decomposition of the conversion cycle of the creditor and the financing cycle of the debtor.

To abstract from influences other than value chain design, all underlying business processes have a standard deviation of 0 days for their duration (i.e. service time). The elimination of business process service time volatility prevents the redesign effect from being masked by the aggregate volatility of all service times in the value chain. The simulation models for the alternative designs also abstract from price volatility, debt default and profit margins. Eliminating price volatility prevents the financial values (e.g. liabilities, turnover) in the models from being distorted by price fluctuations. Debt default would increase the need for external funding, as default implies that customers do not provide the required financial means to compensate the assets that were transferred to them. Finally, profit margins reduce the need for external funding as they imply that the customers provide more financial means to the enterprise then required for replacing the assets that were transferred to these customers. As a result of these abstractions, the remaining variables in the simulation models are the value chain design and the inter-arrival time between the product deliveries in the supply driven value chain (i.e. assuming product supply is the trigger for all other economic events in the value chain model).

Table 2 shows simulation results that originate in a set of 10 simulation runs with $300+$ cases each created by a token generator that varies the inter-arrival time randomly and assigns a value of 1 , representing $€ 1000000$, to each individual token. The original design (i.e. Design 0 ) has a value chain cycle time $^{3}$ of 90 days (i.e. $50+3+30+2+5$ ). The liabilities equal the value of all assets in the value chain (i.e. work in progress, accounts receivable and cash) for which no requiting money outflow has occurred. The need for external funding (i.e. NEF) then represents the liabilities that is not financed by supply chain partners (mostly the supplier, through terms of payment) and for which other funding (e.g. equity, bank loans) needs to be found. Turnover then aggregates the value of all tokens that flow through the value chain during one simulated year (i.e. 360 days). The receivables aggregate the value of all tokens that are occupied by the revenue cycle (during 30 days), work in progress (i.e. WIP) aggregates the value of all tokens that are occupied by the conversion cycle

\footnotetext{
${ }^{3}$ The time between the acquisition of a raw material and the moment the money that is generated by these raw materials, after conversion and sale, is available for a subsequent acquisition of raw materials.
} 
Table 2. Simulation Results for alternative value chain designs (*: in days; **: in $€ 1000000)$

\begin{tabular}{|lllllllll|} 
& \multicolumn{2}{l}{ Design 0 } & \multicolumn{2}{c}{ Design 1 } & \multicolumn{2}{c|}{ Design 2 } & \multicolumn{2}{c|}{ Design 3 } \\
\cline { 2 - 9 } & Avg. & Std. & Avg. & Std. & Avg. & Std. & Avg. & Std. \\
Cycle Time* & 90 & 0 & 65 & 0 & 65 & 0 & 90 & 0 \\
Liabilities*** & 22,4 & 4,5 & 16,4 & 3,8 & 16,9 & 3,9 & 22,4 & 4,5 \\
\hline NEF** & 15,1 & 3,7 & 9,0 & 2,8 & 9,4 & 2,9 & 21,2 & 4,4 \\
Turnover** & 89,5 & $/$ & 89,9 & $/$ & 92,7 & $/$ & 89,5 & $/$ \\
Receivables** & 9,0 & 2,9 & 9,0 & 2,8 & 3,0 & 1,6 & 9,0 & 2,9 \\
WIP** & 12,7 & 3,5 & 6,6 & 2,4 & 13,1 & 3,5 & 12,7 & 3,5 \\
Cash** & 1,7 & 1,2 & 1,7 & 1,2 & 1,8 & 1,2 & 1,7 & 1,2 \\
\hline
\end{tabular}

(during 50 days) and cash aggregates the value of all tokens in the financing cycle (during 5 days).

The first redesign results in a reduction of the value chain cycle time by 25 days. Since the underlying business processes have no variance, the cycle time's standard deviation is 0 . This conversion cycle service time reduction decreases the average value of the liabilities by the same percentage as the value chain cycle time is reduced (i.e. $28 \%$ ), while the average need for external funding is reduced by $40 \%$. Both these reductions originate in a $50 \%$ reduction of the work in progress (i.e. WIP), which represents the value of the assets that are involved in conversion processes. This reduction is the result of a reduced conversion cycle service time and a stable product supply and flow. The second redesign also reduces the value chain cycle time by 25 days and the average liabilities with $28 \%$ and the need for external funding with $40 \%$ due to a $67 \%$ decrease in the value of the accounts receivable, which originates in a shorter term of payment and a stable revenue flow. Finally, redesign 3 shows the effect of a reduced term of payment on an enterprise's need for external funding, as the need for external funding increases with $40 \%$ while the total value of the enterprise's liabilities remains unchanged.

This exhibit motivates business process redesign efforts[15] as it shows that shorter service times in the conversion cycle reduce an enterprise's liabilities and need for external funding, without burdening its customers with an extra need for external funding which may result in a higher cost of capital or increased illiquidity and insolvency risk. This change in the need for external funding for both the seller and the buyer reveals an interference between the seller's revenue cycle and the buyer's acquisition cycle through the shared variable 'term of payment'.

Also aggregate effects of business model changes could be simulated if multiple redesigns are incorporated in a single simulation model run. Through the shared variable 'term of payment', also the propagation of liquidity constrains throughout entire collaboration spaces could be simulated (e.g. liquidity constraints for a customer may evoke delayed payments to its supplier, which increases this supplier's need for external funding, which may lead to delayed payments of this supplier to its own suppliers etc., see e.g. [14]) In a day-to-day planning approach, value chain models as presented here could be used to predict the prolonged term of payment for each individual invoice in the waiting line, based upon a priority algorithm (e.g. first-in-first out, largest debt) and a prediction of the expected incoming money flows, based on the due date of individual claims on customers or predicted sales and terms of payment offered to customers. 


\section{Conclusions and Future Research}

This paper showed that the REA enterprise ontology can be used to guide the construction of business simulation models, including models for simulating collaboration spaces between supply chain partners, value chains and business processes. The main advantage of using the REA ontology to construct business simulation models is that the economic rationale expressed by this ontology facilitates the integration of financial flows in simulation models that are traditionally focused on logistics flows of goods and services, information flows and workflows. The resulting models can support assessing the financial consequences of specific business process and supply chain configurations. For example, the effect of a customer that delays its payments or a supplier that shortens or lengthens its term of payment on an enterprise's cash position can be assessed.

The simulation language used for REA ontology-based business simulation models is the one of the ExSpect tool and is based on the high-level Petri-net formalism. The use of hierarchical Petri-nets allows constructing decomposition hierarchies of discrete event simulation models, such that simulation models at different levels of aggregation (i.e. business process, value chain, collaboration space) can easily be integrated. The use of coloured Petri-nets was key to injecting economic rationale into simulation models built using the REA ontology and the ExSpect tool, as these coloured Petri-nets allow the attribution of economic value to tokens representing economic resources. Finally, timed Petri-nets allow for the representation of actual business process characteristics (e.g. service time).

Since the simulation exhibit presented in this paper abstracts from many natural business variables (e.g. service time variability) and economic variables (e.g. price fluctuations), we intend to elaborate more realistic business cases that demonstrate the use of discrete event simulation models in conceiving and evaluating (alternative) business designs.

\section{References}

1. Geerts, G.L., McCarthy, W.E.: An ontological analysis of the economic primitives of the extended-REA enterprise information architecture. International Journal of Accounting Information Systems 3, 1-16 (2002)

2. Geerts, G.L., McCarthy, W.E.: The Ontological Foundation of REA Enterprise Information Systems. Michigan State University (2004)

3. ISO/IEC: Information technology - Business Operational View Part 4: Business transaction scenario - Accounting and economic ontology. ISO/IEC FDIS 15944-4: 2007(E) (2007)

4. McCarthy, W.E.: The REA Modeling Approach to Teaching Accounting Information Systems. Issues in Accounting Education 18, 427-441 (2003)

5. Dunn, C.L., Cherrington, J.O., Hollander, A.S.: Enterprise information systems: a patternbased approach. McGraw-Hill/Irwin, Boston (2005)

6. McCarthy, W.E.: The REA Accounting Model: A Generalized Framework for Accounting Systems in a Shared Data Environment. Accounting Review 57, 554-578 (1982)

7. Gailly, F., Laurier, W., Poels, G.: Positioning and Formalizing the REA enterprise ontology. Journal of Information Systems 22, 219-248 (2008) 
8. van der Aalst, W.M.P., Hee, K.M.v.: Workflow management: models, methods and systems. MIT Press, Cambridge (2002)

9. Gordijn, J.: Value-based requirements Engineering: Exploring innovative e-commerce ideas. Exact Sciences, Phd. Free University of Amsterdam, Amsterdam, p. 292 (2002)

10. Church, K., Smith, R.: REA Ontology-Based Simulation Models for Enterprise Strategic Planning. Journal of Information Systems 22, 301-329 (2008)

11. Zuberek, W.M., Bluemke, I.: Hierarchies Of Place/transition Refinements In Petri Nets. In: 5th IEEE International Conference on Emerging Technologies and Factory Automation, pp. 355-360. IEEE, Kauai (1997)

12. Porter, M.E., Millar, V.E.: How information gives you competitive advantage. Harvard Business Review 63, 149-160 (1985)

13. Gilman, G.: The manager and the systems concept. Business Horizons 12, 19-28 (1969)

14. Laurier, W., Poels, G.: Simulating Liquidity in Value and Supply Chains. In: Albani, A., Barjis, J., Dietz, J.L.G. (eds.) CIAO!/EOMAS 2009. LNBIP, vol. 34, pp. 40-54. Springer, Heidelberg (2009)

15. Reijers, H.A., Liman Mansar, S.: Best practices in business process redesign: an overview and qualitative evaluation of successful redesign heuristics. Omega 33, 283-306 (2005) 